\title{
Ю.О. Мамонова
}

\section{ВНЕШНИЙ ОБЛИК РУССКОЙ СУХОПУТНОЙ АРМИИ В РУССКО-ЯПОНСКОЙ ВОЙНЕ 1904-1905 ГГ. В СВИДЕТЕЛЬСТВАХ КОРРЕСПОНДЕНТОВ НЕМЕЦКОЯЗЫЧНЫХ ИЗДАНИЙ}

\begin{abstract}
Дается обзор характерных черт внешнего облика рядового и командного состава русской сухопутной армии в Русскояпонской войне 1904-1905 гг. на основе изданных в первые послевоенные годы воспоминаниях, дневниках и письмах военных корреспондентов немецкоязычных изданий - Р. Гедке, О. фон Шварца и А. Шпайца. Определена специфика лежащих в основе исследования источников и влияющих на восприятие русской армии факторов. Выявлено общее и особенное в авторских оценках относительно общефизических характеристик и физических качеств личного состава русской сухопутной армии, сопряженных с состоянием здоровья солдат и офицеров бытовых привычек, а также ряда сопутствующих зрительному восприятию элементов. Установлена и продемонстрирована связь между зафиксированными на страницах воспоминаний явлениями и первоначальными установками репортеров.

Ключевые слова: Русско-японская война 1904-1905 гг.; военные корреспонденты; русская армия; немецкоязычные периодические издания.
\end{abstract}

Развернувшиеся в рамках Русско-японской войны 1904-1905 гг. события приковали к себе внимание ведущих зарубежных периодических изданий, о чем красноречиво свидетельствует численность привлеченных к освещению хода войны корреспондентов. Значительный вклад в осведомленность мировой общественности о положении дел на театре военных действий внесли сопровождающие русскую армию представители прессы - 102 репортера российских изданий и 38 прибывших из-за рубежа журналистов [1. С. 201].

По возвращении в свои страны частью из них были опубликованы воспоминания, дневники и письма. При всем многообразии обстоятельств создания записей, послуживших основой для опубликованных позднее иноязычных сочинений, зарубежные репортеры не преминули возможностью отобразить специфику окружающей и непривычной для них социальной среды. Кроме того, при отсутствии значимых событий или же при невысокой степени информированности о происходящем фокус внимания военных корреспондентов нередко смещался в сторону описания представителей рядового и командного состава вооруженных сил. В связи с этим наибольшую взаимную качественную сопоставляемость работ иностранцев представляется возможным констатировать во фрагментах сочинений, посвященных описанию русской армии.

Немало известно о том, что в данный период являла собой русская армия в целом [2-5], но какой она виделась сторонним наблюдателям, бок о бок с ней находившимся на полях Маньчжурии? По-видимому, этот вопрос на протяжении первых послевоенных лет не являлся безынтересным, что подтверждается развернувшейся деятельностью по переводу сочинений зарубежных журналистов и военных атташе. Так, с 1906 по 1914 г. в свет вышло 32 выпуска серии переводных работ иностранцев, побывавших на театре военных действий Русско-японской войны 1904-1905 гг. (преимущественно военных атташе) [6]. Некоторые пере- водные сочинения издавались отдельно. К некоторым из них российские авторы обращались в поисках ответов на многочисленные критические замечания в адрес русской армии, снискавшей после Русско-японской войны 1904-1905 гг. славу «войска без доблести» [7], подчеркивая при этом факт наличия благоприятных оценок на фоне преимущественно недружественного настроя иностранцев.

Вместе с тем целый пласт воспоминаний остался незатронутым, в том числе наследие некоторых военных корреспондентов немецкоязычных изданий, составляющих источниковую базу данной статьи: Рихарда Гедке [8], Оскара фон Шварца [9] и Александра Шпайца [10]. Преимущество данных свидетельств обусловлено тем, что они не были стеснены цензурными предписаниями в противоположность статьям и телеграммам, отправляемым в редакции периодических изданий с фронта. В частности, это наглядно демонстрирует собрание предназначенных для публикации в газете «Berliner Tageblatt» писем отставного полковника Генерального штаба Р. Гедке, созданных с оглядкой на военную цезуру [8]. Наличие внесенных позднее примечаний и уточнений автора позволяет уяснить, что в действительности скрывалось за некоторыми обтекаемыми формулировками, представленными в отправленном в редакцию издания тексте.

Под обложкой книги другого автора, репортера «Berliner Lokal-Anzeiger» и лейтенанта в отставке О. фон Шварца собраны воедино непосредственно дневниковые записи и заметки об увиденном, созданные по прошествии некоторого времени. Данный источник наиболее ярко демонстрирует отдаленность преподносимых со страниц периодического издания сообщений от окружающей автора действительности. Виной этому являлись чинимые военной цензурой препятствия, в связи с чем условия своей профессиональной деятельности характеризовались военным корреспондентом как «почти невыносимые» [9. S. 302]. 
В данном случае следует иметь ввиду и возможную предвзятость О. фон Шварца к принимающей корреспондентов стороне. Русский народ в целом он представляет исключительно в негативном свете; уже на первых страницах вводной статьи журналиста мы видим рассуждения о «русской угрозе» с массой резких высказываний о взаимной ненависти народов, господствующей в умах русских людей «химере славянофильства» и опасности грядущего противостояния [9. S. 1-6]. Впрочем, словам очевидцев о подвигах русских солдат и офицеров он верит вполне охотно.

Статьи австро-венгерского подданного, ротмистра запаса А. Шпайца в немецкоязычной венгерской газете «Pester Lloyd» также существенно уступают в информативности опубликованным в 1906 г. в Вене воспоминаниям. Находясь на заключительном этапе своего путешествия вдали от почтово-телеграфных учреждений, корреспондент не имел возможности регулярно отправлять в редакцию периодического издания какие-либо сведения. Так, в просмотренных выпусках газеты «Pester Lloyd» за 7 месяцев, охватывающих время пребывания А. Шпайца на театре военных действий, следование к нему и возможные временные затраты при доставке письма к месту назначения, было выявлено лишь семь совпадающих по содержанию с книгой статей под псевдонимом [11-17]. Благодаря отсутствию существенных корректировок текста было установлено авторство репортера. Соответственно, лишь малая часть увиденного была доступна читателям и опубликована своевременно, и полная картина способна сложиться исключительно при опоре на изданные воспоминания.

Как правило, заявляемая авторами мемуаров непредвзятость в изложении вовсе не исключает пристрастности, стереотипности, некоторого эмоционального вовлечения и сопереживания (степень которого, впрочем, значительно варьируется от источника к источнику). Вышеуказанные источники, в силу их специфики, требуют принятия во внимание внешнеполитической обстановки и межнациональных отношений. В данном случае следует отметить важнейшую особенность воспоминаний, составляющих основу статьи, симпатии журналистов немецкоязычных изданий к сторонам конфликта представляются не столь очевидными, в отличие от подданных других стран-лидеров по количеству присутствующих на театре военных действий представителей прессы: близкой к России Франции и прояпонски настроенным Англии и США. В этой связи особенно интересна разнонаправленность тенденций в работах О. фон Шварца, чья позиция по поводу межнациональных отношений была представлена выше, и Р. Гедке. Согласно свидетельствам последнего, немецкое имя в русском офицерском корпусе почитаемо и популярно, особенно воодушевленно отзываются о политике «благородного немецкого рыцаря» Вильгельма II, вспоминая его слова о «желтой опасности». В целом «немец может только желать, чтобы заграницей говорили о нашем властителе с таким глубоким уважением» [8. S. 38-39].

Противоречивые сведения двух корреспондентов могут быть связаны как с личными взглядами авторов, им соответствующими умышленными или непреднамеренными преувеличениями, стремлением представить миру определенную информацию при осознании оказываемого влияния на читателя, так и с совершенно иным опытом. Вышеуказанные выводы Р. Гедке базировались, прежде всего, на беседах с генералитетом и ограниченным кругом лиц, знающих французский или немецкий языки. О. фон Шварц же, скитаясь в поисках хоть каких-нибудь новостей (недостаток последних, впрочем, по словам всех журналистов, был крайне насущной проблемой для каждого из них), временного жилища и продовольствия, проявляя интерес к различным сплетням и авантюрам, увидел больше сторон кипящей в пределах театра военных действий жизни, и его путь видится наиболее насыщенным событиями. Что же касается А. Шпайца, то им подобные вопросы не затрагивались, а на страницах его воспоминаний просматривается глубокая симпатия к русским людям в целом и русской армии в частности. В данном контексте следует отметить, что в основе принятого им решения о поездке на фронт лежало стремление что-либо противопоставить предубежденной западной прессе, раскрыть «язвительную ложь» в отношении русской армии и ее руководства $[10$. S. 21], что также необходимо иметь ввиду.

Приняв во внимание многообразие факторов, способных повлиять на восприятие репортерами действительности, можно заключить, что достаточная степень однородности источников не может отменить дифференцированного подхода к каждому из них. Немаловажным преимуществом свидетельств военных корреспондентов немецкоязычных изданий является незначительный период времени, отделявший знакомство авторов с русской армией и публикацию воспоминаний: вышеприведенные работы изданы в 1905-1906 гг., что уменьшает вероятность вторичного наслоения ошибок памяти и связанной с эволюцией взглядов авторов аберрации.

Описание внешнего облика рядового и командного состава русской армии занимает особое место в свидетельствах иностранцев, фиксирующих непримечательные для соотечественников детали. Содержание воспоминаний и дневников журналистов позволяет сделать вывод о том, что физические качества русских солдат и офицеров представляли для А. Шпайца, Р. Гедке и О. фон Шварца немалый интерес.

Р. Гедке в отправленных в редакцию письмах неоднократно восхищался суровым внешним видом повстречавшихся ему офицеров и солдат, их сложением и физическими качествами. Особенно щедрым на похвалу автор был по отношению к сибирякам: «...я могу только сказать, что этот сибирский рядовой состав вряд ли уступает в своих физических качествах лучшему 
пополнению нашей армии, если можно по собравшимся здесь 200 мужчинам заключать об остальных. Я редко видел такой подбор обветренных, коренастых и отчасти очень высоких парней вместе» [8. S. 36]. Таковым был его взгляд на собранных на вокзале Петропавловска резервистов. В дальнейшем репортер только убеждался в своих оценках, продолжая подробно описывать внешний вид сибирских запасников и характеризуя их «людьми великолепными». Сибирь, по его словам, является поставщиком лучших пополнений армии по причине суровых погодных условий и «сносной состоятельности» крестьян. Любопытно, что с течением времени автор не менял своей точки зрения и продолжал акцентировать внимание читателя на прекрасной физической форме и солдат, и офицеров, несколько дополняя свои оценки тем, что время от времени он все-таки замечал «вновь призванных резервистов, несмотря на их длинное и часто бледное тело, выглядевших голодающими и вялыми, будто бы вдобавок ко всему имелась нужда, истощающая неполноценным питанием» [Ibid. S. 337].

Что касается русского офицерского корпуса, то, невзирая на отсутствие недостающей ему выправки, он отмечает впечатляющий внешний вид офицеров, так как он «сплошь состоит из прекрасных, статных, часто импозантных фигур», автор видит в нем «элиту народа» и признает его превосходящее в этом отношении положение в сравнении с германским офицерским корпусом. Впрочем, объяснение этому он находит весьма утешительное для немецкого читателя: «немецкая высокая культура взрастила более изящные и приличествующие виды» [Ibid. S. 345].

В целом Р. Гедке видел в русских антропологическое сходство с немцами, в отличие от доказывающего превосходство последних О. фон Шварца. Автор, что показательно, для подтверждения своих взглядов к описанию физических данных не прибегал, а встречающиеся в его воспоминаниях детали не выбиваются из создаваемой корреспондентами картины. В повествовании о боях в Дашичао, основанном на свидетельствах очевидцев сразу же после сражения, сибиряки характеризуются им непоколебимыми, а в штыковом бою превосходство русского в сравнении с японцем ввиду его физических особенностей признается очевидным: русский солдат обладал внушительной физической силой, был массивным и неуклюжим, а «стоическое спокойствие его совсем редко покидает даже в самой большой боевой жаре, когда с фанатичной яростью атакуют вспыльчивые азиаты» [9. S. 92]. Полковник С.Ф. Добротин сравнивал этот штыковой бой с борьбой между слоном и тигром, в котором первый в большинстве случаев остается победителем. В данном случае репортером представлена скорее точка зрения русского комбатанта, перетекающая в свою собственную. Ход сражения у Дашичао не давал повода корреспонденту не верить впечатлениям самих участников событий, которые благополучно наслаивались на соб- ственный опыт журналиста. Отставной полковник Р. Гедке, опираясь на увиденное им в течение пребывания на театре военных действий, также подтверждал безусловное преимущество в телосложении и физической силе русского солдата, однако японцы не казались ему слабым противником: «...многолюдная Япония имела относительно небольшую армию, что позволяло ей осуществлять суровый отбор претендентов в ее ряды, которые поголовно были маленькими, но коренастыми и крепкими парнями, ни в коем случае не боящимися штыкового боя с противником» [8. S. 337].

Bce военные корреспонденты солидарно подчеркивают глубоко впечатляющую выносливость русского солдата. А. Шпайц, находясь вблизи д. Падязы в феврале 1905 г., на страницах своих воспоминаний отмечал: «...едва ли будет иметься на свете более непритязательный и выносливый солдат чем русский. Жаль этот восхитительный материал!» [10. S. 229]. Подобные замечания встречаются на страницах его книги многократно, в особенности в эпизодах с раненными, стоически переносящими боль, что зафиксировано и Р. Гедке: «...даже в смертельной агонии это - храбрые мужчины» [8. S. 282].

Стойкость и выносливость в любых условиях становились поводом для искреннего восхищения иностранцев. «Русский солдат выносит погодные невзгоды гораздо лучше слабого японского, в этом не может быть никакого сомнения, - заключает журналист, - в этой пассивной устойчивости любого рода неприятности состоит одно из основных преимуществ русского народа» [Ibid. S. 159]. Даже О. фон Шварц свидетельствовал о «героической выносливости русских солдат, достойной наивысшего восхищения», проявленной в сезон дождей, в условиях которого «одежда, вооружение и продовольственное снабжение войск были неудовлетворительны как никогда прежде» [9. S. 104].

Впрочем, подобные проявления не всегда оценивались военными корреспондентами исключительно комплиментарно. Эпизодически данная особенность именовалась как «граничащее с летаргией терпение» [10. S. 196] и связывалась со свойственными любому русскому человеку чертами: доходящей до крайности флегматичностью, медлительностью, отсутствием инициативы и энергии.

В заданных рамках особый интерес представляют выводы авторов о состоянии здоровья военнослужащих, отчасти уже представленные выше словами Р. Гедке о периодически встречающихся истощенных запасниках. Ряд касающихся этой темы деталей черпались авторами в конкретной обстановке и имели ситуативный характер. Так, О. фон Шварц, характеризуя попутчиков в поезде, утверждал: «...примерно из 60 господ, которые ехали со мной, минимум 20 по причине недостающих знаний - это касалось всех офицеров запаса - или из-за болезней были абсолютно неспособными к исполнению серьезных обязанностей, которые к ним предъявлялись» [9. S. 36]. Следует отметить, 
что под болезнями в данном случае подразумевалась нездоровая тяга русского человека к спиртному.

Воспоминания репортера изобилуют примерами непристойного поведения, разбойных нападений и прочих последствий этого пагубного пристрастия. На страницах книги нередко можно встретить описания офицеров, находящихся в состоянии алкогольного опьянения, а большинство трезвых и здоровых представителей офицерского корпуса, по мнению автора, непременно имели прусское происхождение или являлись представителями гвардии [9. S. 36].

Как правило, пристрастие русского человека к алкоголю является излюбленной темой рассуждений. Настоящая тема фигурирует в каждом источнике, однако удостаивается различных оценок, которые находятся в корреляции с личными симпатиями и настроем авторов. Вина за непомерное потребление спиртного и А. Шпайцем, и Р. Гедке возлагается исключительно на власть [8. S. 336; 10. S. 249]. По их мнению, русский человек не знал в этом меры, но в целом пил не больше англичанина или немца.

В целом все военные корреспонденты при упоминаниях о некоторых случаях заболевания дизентерией, отмечали относительный порядок со здоровьем русской армии, невзирая на всю неблагоприятность окружающих условий, притом основания для этого каждым корреспондентом виделись по-разному, что ярким образом иллюстрирует настрой каждого автора в отдельности. В частности, Р. Гедке считает, что высшей похвалы за оправдавшие себя усилия достойна медицинская служба [8. S. 159]; О. фон Шварцу это кажется случайностью («это чудо, что никакая эпидемия не вспыхивает!» [9. S. 63]). А. Шпайц видит в этом заслугу в укоренившихся привычках самих солдат и офицеров, а именно в удивительной для иностранца страсти русского человека к чаю: «Это не преувеличение, если говорят, что русская Маньчжурская армия была обязана ее превосходным здоровым состоянием чаю. Зародыш всех инфекционных заболеваний лежит в большинстве случаев в некипяченой плохой воде. <..> приученный к чаю русский никогда не будет пить обычную воду...» [10. S. 113].

Примечательно, что эта привычка отмечалась всеми репортерами. На страницах воспоминаний Р. Гедке упоминалось приготовление чая в траншеях [8. S. 297], О. фон Шварц же, который подробнейшим образом описывал тягу русских солдат и офицеров к спиртному, в разы чаще упоминал о пьющих чай солдатах и офицерах вне зависимости от каких-либо обстоятельств: «...снова и снова чай, чай, который расходовался в чрезмерном количестве утром, днем и вечером, без которого русский солдат, по-видимому, вообще жить не может» [9. S. 291].

Представляется необходимым отметить, что вещевое и продовольственное обеспечение войск, внесшее значительный вклад в подтвержденное корреспондентами благоприятное самочувствие командного и рядо- вого состава, единогласно признано военными журналистами более чем удовлетворительным. Имеющиеся недочеты, как правило, исправлялись, а с потребностями считались. В частности, летом 1904 г. военным репортерам нередко приходилось видеть солдат, шагающих в изорванной обуви или же вовсе без нее [8. S. 316; 9. S. 94], но по прошествии времени журналисты констатировали исчезновение данной проблемы. Согласно наблюдениям А. Шпайца, оснований верить слухам о нехватке теплых вещей не было, и «против холода армия вооружена превосходно» [10. S. 245].

Эпизодически доносившиеся с полей вооруженного противостояния сведения о голодающих и бедствующих солдатах, по мнению иностранцев, являлись выдумкой [Ibid. S. 147], а их здоровый внешний вид являлся тому подтверждением. Симптоматичным представляется тот факт, что отдельно подчеркнутая каждым военным репортером «склонность русского солдата к попрошайничеству», воплощенная в многочисленных жалобах на отсутствие материальных средств и голод, прошении милостыни (преимущественно у иностранцев), а также в предложении различного рода услуг, продаже формы и имущества [8. S. 344; 10. S. $242]$, вовсе не пошатнула авторов в этой убежденности. Жадный до подобных неприглядных проявлений в «русской Маньчжурии» О. фон Шварц, заметив гневно жалующегося на отсутствие хлеба и двухдневный голод солдата, предположил: «Это было очевидным лукавством, парень выглядел для этого слишком толстым и хорошо откормленным» [9. S. 245].

Помимо заботы командования, весомый вклад в это могли внести другие факторы. В частности, А. Шпайц отмечает, что этому способствовал вид боевых действий: «...отступающую армию легче снабжать продовольствием <..>. Кроме того, весь поход состоял из ряда операционных застоев, во время которых продовольственное снабжение было проще» [10. S. 148], хотя и не отрицает, что были и голодные дни, подразумевая ситуацию после сражения под Мукденом, что, как правило, стойко переносилось.

Следует добавить, что велика в этом заслуга и самих комбатантов. Помимо того, что в сравнении с представителями иностранных армий русский солдат выигрывал в непритязательности, что не раз отмечалось корреспондентами, он также виделся иностранцам вполне самостоятельным в вопросах создания благоприятных для себя условий. В частности, Р. Гедке особенно заостряет внимание на способности русского солдата к «самоотверженному обеспечению хорошего самочувствия», где проявляется его независимость и изобретательность, в отличие от германского солдата, который привык к большой опеке со стороны офицеров. В связи с тем, что благосклонность руководства к нему пассивна и выражается она в «напряжении его физических и моральных сил не до конца», русский солдат зачастую предоставлен сам себе и ему без труда удается многое вовсе при отсутствии офицера: поение 
лошадей, получение фуража и продовольствия, марши многочисленных транспортных средств, замена боеприпасов, - «солдат делает свое дело разумно и хорошо, без помощи, надзора и без разногласий» [8. S. 343] Лишь единожды, отмечает отставной полковник, он наблюдал внутренний беспорядок - при отступлении от Ляояна и Янтая.

В пользу его заключений свидетельствуют и другие авторы. О. фон Шварц многократно становился свидетелем подтверждающих это ситуаций и, кроме того, не раз ему казалось, что войска занимались целыми днями исключительно заботой о собственном продовольственном снабжении [9. S. 182]. Тем не менее иногда способность позаботиться о себе его приятно удивляла, например, он зафиксировал отсутствие какого-либо беспорядка и спора возле единственного источника воды в одной из деревень в окрестностях Ляояна при том, что возле него теснились множество военнослужащих, лошадей, и никакой офицер не был откомандирован для поддержания порядка. «Флегматичность помогает русскому солдату легко преодолеть такие ситуации», - заключает корреспондент [Ibid. S. 114]. C вышеуказанными авторами в данном вопросе совершенно солидарен и А. Шпайц, также усматривающий причины этого в особенностях русского характера, воспитанного «русской системой» и суровыми природными условиями.

Необходимо отметить и то, что не раз авторами упоминалась позволяемая офицерами излишняя загру- женность войск «всяким барахлом», например, ведрами, полевыми котлами, чайниками, жестяными тарелками, разнообразной домашней утварью и прочими «исключительно полезными», по их мнению, предметами, от чего страдали маршевые возможности подразделений [8. S. 43, 262, 271; 9. S. 62, 212].

Таким образом, в свидетельствах военных корреспондентов немецкоязычных изданий Р. Гедке, О. фон Шварца и А. Шпайца просматривается разветвленность оценочных суждений, смещение акцентов на те или иные детали образа русского солдата и офицера, что продиктовано изначальными установками авторов, их личными симпатиями и побудительными к путешествию в Маньчжурию мотивами.

В целом внешний облик присутствующих на сухопутном театре военных действий Русско-японской войны 1904-1905 гг. представителей рядового и командного состава русской армии наделялся рядом характеристик: суровый внешний вид, плотное телосложение, неповоротливость и медлительность, непреодолимое пристрастие к спиртному, а также просматривающаяся во всех внешних поведенческих проявлениях флегматичность и порой безграничное терпение. Авторы опровергают слухи о неудовлетворительном продовольственном обеспечении, отмечают большую самостоятельность рядового состава во многих вопросах, его организованность, нередко повествуют о благоприятном самочувствии военнослужащих, ухудшающемся во время отступлений, но стремительно восстанавливаемом

\section{ЛИТЕРАТУРА}

1. Военная энциклопедия. СПб. : Т-во И.В. Сытина, 1911-1915. Т. 13.

2. Керсновский А.А. История русской армии. Т. 3: 1881-1915 гг. М., 1994.

3. Зайончковский П.А. Самодержавие и русская армия на рубеже XIX-XX столетий: 1881-1903 гг. М., 1973.

4. Бескровный Л.Г. Армия и флот России в начале XX в.: Очерки военно-экономического потенциала. М., 1986.

5. Волков С.В. Русский офицерский корпус. М., 2003.

6. Русско-японская война в наблюдениях и суждениях иностранцев. СПб., 1906-1914. Вып. 1-32.

7. Абамелек-Лазарев С.С. Сказания иностранцев о русской армии в войну 1904-1905 гг. СПб., 1912. С. 2.

8. Gädke R. Kriegsbriefe aus der Mandschurei. Berlin und Leipzig, 1905.

9. Schwartz O. von. Zehn Monate Kriegskorrespondent beim Heere Kuropatkins. Persönliche Erlebnisse und kritische Betrachtungen aus dem russisch-japanischen Kriege. Berlin, 1906.

10. Spaits A. Mit Kosaken durch die Mandschurei: Erlebnisse im russisch-japanischen Kriege. Vienna, 1906.

11. Pester Lloyd. 1904. 21. Dezember.

12. Pester Lloyd. 1905. 31. Januar.

13. Pester Lloyd. 1905. 4. Februar.

14. Pester Lloyd. 1905. 19. Februar.

15. Pester Lloyd. 1905. 26. Februar.

16. Pester Lloyd. 1905. 21. März.

17. Pester Lloyd. 1905. 3. Mai.

Yulia O. Mamonova. Novosibirsk State University (Novosibirsk, Russia). E-mail: iulia.mamonova@gmail.com WAR CORRESPONDENTS OF GERMAN-LANGUAGE PERIODICALS ABOUT THE RUSSIAN LAND FORCES IN THE RUSSO-JAPANESE WAR 1904-1905: VISUAL ASPECT

Keywords: the Russo-Japanese war; 1904-1905; war correspondents; Russian army; German-language periodicals.

The aim of the submitted article is to analyze how the outward appearances of Russian land forces were perceived by war correspondents of German-language periodicals in Russo-Japanese war of 1904-1905. The main sources for the research were published memoirs, diaries and letters from representatives of German and Austro-Hungarian press: primarily retired being a colonel and correspondent of the daily "Berliner Tageblatt" Richard Gaedke, retired lieutenant, war correspondent of the "Berliner Lokal-Anzeiger" Oscar von Schwartz and retired captain of the cavalry from the newspaper "Pester Lloyd" Alexander Spaits. In the first post-war years, these witnesses of the Russian participation in the Russian-Japanese war of 1904-1905 in Manchuria had published the materials collected about it. The range of the topics covered by these correspondents was wide and various, but the appearance of the Russian soldiers and officers 
is described in great detail. The reason for this is that very often representatives of the press focused on the social environment, which was unusual for them. In this regard, the visual aspect of perception is in the focus of attention - information about physical abilities of the combatants, their health and household habits, characteristics of external behavioral manifestations and other problematic issues that have been considered and analyzed in the present article. Comparison of the data from these sources shows similarity between the described characteristics of the Russian forces in Manchuria and a difference between their interpretations. War correspondents of German-language periodicals R. Gaedke, O. von Schwartz and A. Spaits saw the Russian soldiers and officers as slow, sluggish men with a robust constitution and impressive physical force. Their addiction to alcohol, calmness, unpretentiousness and the boundless patience shown in the most adverse conditions were noted. Authors have refuted the information about unsatisfactory food security and the physical condition of the Russian land forces on the pages of their works and have stressed big independence of enlisted men in many everyday and organizational issues. In order to prove it, the authors have cited examples from the life on the Russian positions in Manchuria during the war between Russia and Japan. Determination of the specifics of the sources on which the research was based and research of conditions of their creation has shown interrelation between author's estimates of the state of the Russian army and personal sympathies of authors, their mood, motives, incentive for a travel to Manchuria. This set of factors led to the shift of emphases on details of outward appearance of Russian soldiers and officers in Manchuria during the Russo-Japanese war of 1904-1905.

\section{REFERENCES}

1. Novitsky, V.F. et al. (ed.) (1911-1915) Voennaya entsiklopediya [Military Encyclopedia]. Vol. 13. St. Petersburg: I.V. Sytin.

2. Kersnovsky, A.A. (1994) Istoriya russkoy armii [History of the Russian army]. Vol. 3. Moscow: Golos.

3. Zayonchkovsky, P.A. (1973) Samoderzhavie i russkaya armiya na rubezhe XIX-XX stoletiy: 1881-1903 gg. [Autocracy and the Russian army at the turn of the 20th century: 1881-1903]. Moscow: Mysl'.

4. Beskrovnyy, L.G. (1986) Armiya i flot Rossii v nachale XX v.: Ocherki voenno-ekonomicheskogo potentsiala [The army and navy of Russia in the early 20th century: Essays on the military-economic potential]. Moscow: Nauka.

5. Volkov, S.V. (2003) Russkiy ofitserskiy korpus [Russian officer corps]. Moscow: Tsentrpoligraf.

6. Barcini, L. et al. (1906-1914) Russko-yaponskaya voyna v nablyudeniyakh i suzhdeniyakh inostrantsev [Russian-Japanese war in the observations and judgments of foreigners]. St. Petersburg: V. Berezovsky.

7. Abamelek-Lazarev, S.S. (1912) Skazaniya inostrantsev o russkoy armii v voynu 1904-1905 gg. [Foreign tales about the Russian army in the war of 1904-1905]. St. Petersburg: Rodnik. pp. 2.

8. Gädke, R. (1905) Kriegsbriefe aus der Mandschurei. Berlin und Leipzig: Luckhardt.

9. Schwartz, O. von. (1906) Zehn Monate Kriegskorrespondent beim Heere Kuropatkins. Persönliche Erlebnisse und kritische Betrachtungen aus dem russisch-japanischen Kriege. Berlin: [s.n.].

10. Spaits, A. (1906) Mit Kosaken durch die Mandschurei: Erlebnisse im russisch-japanischen Kriege. Vienna: [s.n.].

11. Pester Lloyd. (1904) 21 st December.

12. Pester Lloyd. (1905) 31 st January.

13. Pester Lloyd. (1905) 4th February.

14. Pester Lloyd. (1905) 19th February.

15. Pester Lloyd. (1905) 26th February.

16. Pester Lloyd. (1905) 21st March.

17. Pester Lloyd. (1905) 3rd May. 